\title{
Water Oxidation Mechanism for 3d Transition Metal Oxide Catalysts under Neutral Condition
}

\author{
Hongmin Seo, Kang Hee Cho, Heonjin Ha, Sunghak Park, Jung Sug Hong, \\ Kyoungsuk Jin, and Ki Tae Nam ${ }^{\dagger}$ \\ Department of Materials Science and Engineering, Seoul National University, Seoul 08826, Korea
}

(Received January 12, 2017; Accepted January 19, 2017)

\begin{abstract}
Electrochemical water splitting to produce hydrogen energy is regarded as a promising energy conversion process for its environmentally friendly nature. To improve cell efficiency, the development of efficient water oxidation catalysts is essentially demanded. For several decades, 3d transition metal oxides have been intensively investigated for their high activity, good durability and low-cost. This review covers i) recent progress on $3 \mathrm{~d}$ transition metal oxide electrocatalysts and ii) the reaction mechanism of oxygen evolving catalysis, specifically focused on the proposed pathways for the O-O bond formation step.
\end{abstract}

Key words : Transition metal oxides, Electrodes, Water oxidation, Electrocatalyst, O-O bond formation

\section{Introduction}

$\mathbf{R}$ ecently, research on environment-friendly and renewable energy sources to replace fossil fuels are ongoing and active. Various alternative energies such as solar, wind and tidal energies have been proposed but undesirable required operating conditions limits their practical application. Hydrogen energy, on the other hand, can be stably produced regardless of external condition and is easy to store in the form of hydrogen gas. Furthermore, hydrogen possesses high energy density ( 142 kJ/g) compared to oil $(46 \mathrm{~kJ} / \mathrm{g})$ and natural gas $(47.2 \mathrm{~kJ} / \mathrm{g})$. In this regard, it is attracting attention as a future alternative energy resource. Recently, the department of Energy (DOE) in the U.S. proposed three targets, including targets for hydrogen production, transfer and storage; the DOE target for 2020 of $44.7 \mathrm{kWh}$ of energy consumption for $1 \mathrm{~kg}$ of hydrogen production through water electrolysis.

Currently, most hydrogen gas is produced through the gas reforming process, which unavoidably yields $\mathrm{CO}$ and $\mathrm{CO}_{2}$ by-products. Electrochemical water splitting, which operates the reaction with external potential bias, has recently come to be considered as a beneficial and environmentally friendly method, because it does not produce any greenhouse gas. ${ }^{1,2)}$ Detailed reaction equations can be described in following half-cell reactions.

$$
2 \mathrm{H}_{2} \mathrm{O} \leftrightarrow 2 \mathrm{H}_{2}+\mathrm{O}_{2} \quad \mathrm{E}=1.23 \mathrm{~V}
$$

\footnotetext{
Corresponding author: Ki Tae Nam

E-mail : nkitae@snu.ac.kr

Tel : +82-2-880-7094 Fax : +82-2-880-7094
}

$$
\begin{aligned}
& 4 H^{+}+4 e^{-} \leftrightarrow 2 H_{2} \quad E_{c}=0-0.0592(p H) V(\text { vs.NHE }) \\
& O_{2}+4 H^{+}+4 e^{-} \leftrightarrow 2 H_{2} O \quad E_{a}=1.23-0.0592(p H) V(v s . N H E)
\end{aligned}
$$

The hydrogen evolution reaction (HER) proceeds at the cathodic side, while the oxygen evolution reaction (OER) happens at the anodic side. Thermodynamically, $1.23 \mathrm{~V}$ vs. RHE is needed to initiate the water splitting reaction. Unfortunately, practically, a potential higher than $1.23 \mathrm{~V}$ is required and that additional potential is defined as the overpotential.

Moreover, when considering the generation of an additional resistance factor $\left(\mathrm{R}_{\mathrm{s}}\right)$ by electric conductivity and ion mobility, the overall overpotential required for water electrolysis can be expressed as in the equation below.

$$
\eta_{t o t}=\eta_{c}+\eta_{a}+i R_{s} \quad\left(i=i_{c}+i_{c}\right)
$$

Therefore, the fundamental issue is to decrease the total overpotential value in the electrolysis system. Engineering issues such as type of working electrode, electrolysis cell configuration and mass transfer are important tasks to be optimized (Fig. 1). Above all, the crucial thing is to develop efficient catalytic materials for each half-cell reaction.

Water oxidation, due to its slow kinetics, is a bottleneck for the overall water oxidation process. ${ }^{3-5)}$ In the water oxidation reaction, 4 electrons and 4 protons are required in multi-step processes and the formation of single $\mathrm{O}-\mathrm{O}$ bond is thermodynamically difficult. Therefore, the value of the overpotential for water oxidation is generally much higher than that of HER.

In this regard, substantial efforts have been devoted to the discovery of efficient OER catalysts. For instance, precious metal-based catalysts, such as those based on Ir and 
(a)

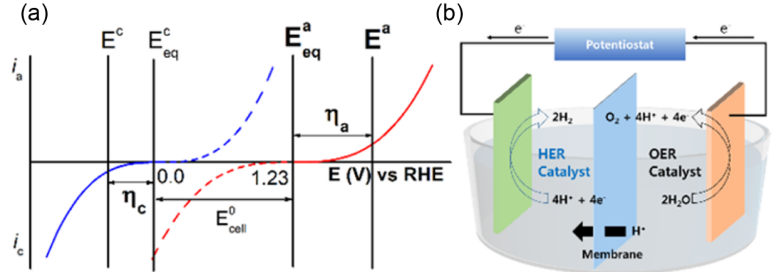

Fig. 1. (a) I-V curve for the overall water splitting reaction (b) Electrochemical system for water splitting.

$\mathrm{Ru}$, have been studied for their superior activity. ${ }^{6-8)}$ However, the scarcity and high price of these materials remain as critical barriers. From this point of view, 3d transition metal oxides are promising materials due to their earthabundant nature and robust stability. Particularly, various $\mathrm{Mn}$, Co and $\mathrm{Ni}$ oxide electrocatalysts have been developed, whereas $\mathrm{Cu}$ and $\mathrm{Fe}$ oxide catalysts have been only rarely reported.

In this review, we cover recent progress in $3 \mathrm{~d}$ transition metal oxide OER catalysts. Representative discoveries of each catalyst and an activity comparison are introduced. Moreover, we will further focus on the water oxidation mechanism in heterogeneous catalysts. Specifically, proposed pathways for the formation of $\mathrm{O}-\mathrm{O}$ bond are summarized. Recent studies on two hypotheses, the acid-base (AB) mechanism and the radical-coupling (RC) mechanism are described in detail.

\section{3d-Transition Metal Oxide Water Oxidation Electrocatalysts}

First row 3d transition metal-based catalysts have been actively researched in terms of the oxygen evolution reaction. Active research has been done in fields of $\mathrm{Mn}, \mathrm{Ni}$ and Co based catalysts, while only few studies have been performed for $\mathrm{Fe}$ and $\mathrm{Cu}$ based catalysts (Fig. 2). Electrochemical measurements of all of the catalysts that we will discuss below proceeded in neutral conditions.

\subsection{Manganese based electrocatalysts}

Various research groups have developed manganese based electrocatalysts with mixed valency; these electrocatalysts exhibit superior performance. Driess's group developed amorphous $\mathrm{MnO}_{\mathrm{x}}$ nanoparticles using ceric ammonium nitrate $(\mathrm{CAN})$ as a chemical oxidant (Fig. 3(a)). ${ }^{9)}$ The amorphous $\mathrm{MnO}_{\mathrm{X}}$ compound was found to have higher activity than that of inactive crystalline $\mathrm{MnO}$ nanoparticles. The researchers proposed that the improved catalytic activity in amorphous $\mathrm{MnO}_{\mathrm{x}}$ could be attributed to the change of the average oxidation state from 2.0 to 2.5 via CAN treatment.

Mn oxide catalysts with mixed valency were also synthesized by electrodeposition method. Dau's group developed $\mathrm{MnO}_{\mathrm{x}}$ catalysts via electrodeposition and estimated the average oxidation state of $\mathrm{Mn}$ (Fig. 3(b)). ${ }^{10)}$ The values of the oxidation state in active and inactive $\mathrm{MnO}_{\mathrm{x}}$ films were 3.8 and 4.0, respectively. In Nocera's group, electrodeposited manganese oxide films $\left(\mathrm{MnO}_{\mathrm{X}}\right)$ were proposed as promising stable catalysts for water oxidation at neutral $\mathrm{pH}$ (Fig. 3(c)). ${ }^{11)}$ They revealed two competing pathways under neutral $\mathrm{pH}$, a one-proton coupled one-electron transfer (PCET) process and an $\mathrm{Mn}(\mathrm{III})$ disproportionation reaction. Additionally, Kuo's group reported mesoporous $\mathrm{MnO}_{\mathrm{x}}$ with high surface area fabricated via a single-step soft-templated wet-chemistry approach (Fig. 3(e)). ${ }^{12)}$

Nakamura's group synthesized $\mathrm{MnO}_{2}$ nanoparticles and detected reaction intermediates by in-situ UV-vis spectroscopy. ${ }^{13)}$ Spectra related to $\mathrm{Mn}(\mathrm{III})$ species were observed with an accompanying increase of the catalytic current density. It was revealed that $\mathrm{Mn}(\mathrm{III})$, which is inherently unstable at neutral $\mathrm{pH}$ due to the disproportionation reaction, served as the precursor of the catalysis. Furthermore, in subsequent research, the group generated N-Mn bonds on the surface of $\mathrm{MnO}_{2}$ via a ligand exchange with poly(allylamine hydrochloride) (PAH). ${ }^{14)}$ The N-Mn bonds restricted the disproportionation process and stabilized the $\mathrm{Mn}$ (III) under neutral $\mathrm{pH}$. Therefore, the effect of the ligand exchange method decreased the onset potential by $\sim 500 \mathrm{mV}$ for the $\mathrm{MnO}_{2}$ catalysts.

Nam's group developed $\mathrm{Mn}_{3}\left(\mathrm{PO}_{4}\right)_{2}-3 \mathrm{H}_{2} \mathrm{O}$ with asymmetric geometry and found that it had superior efficiency. ${ }^{15)}$ Also, after synthesizing various catalysts with different Mn oxidation states by extracting $\mathrm{Li}$ atom from as-synthesized $\mathrm{LiMnP}_{2} \mathrm{O}_{7}$, they found enhanced water-splitting perfor-

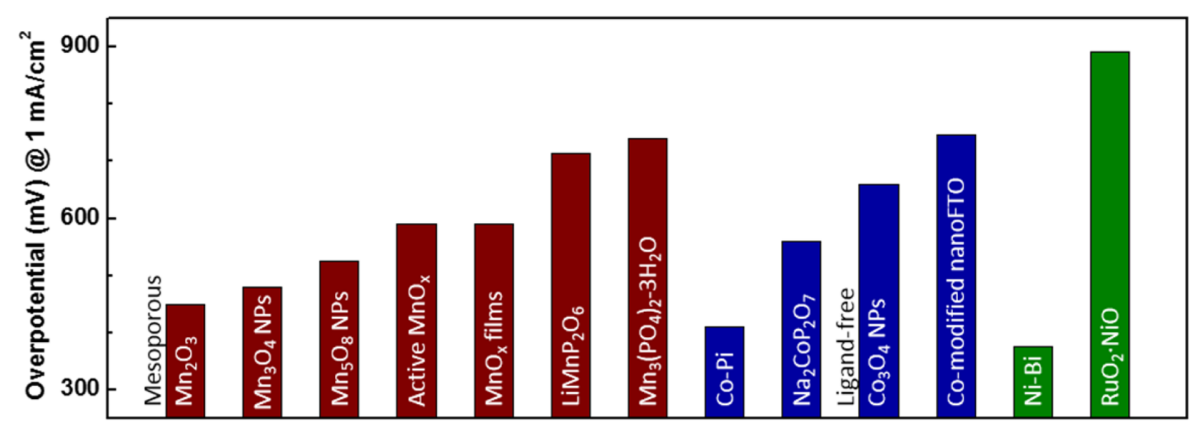

Fig. 2. Overpotentials of various $\mathrm{Mn}$-, Co- and Ni-based electrocatalysts at $1 \mathrm{~mA} / \mathrm{cm}^{2}$. Activity for the Mn-(wine) and Co-(blue) based electrocatalysts are measured under neutral condition, while nickel borate $(\mathrm{Ni}-\mathrm{Bi})$ and $\mathrm{RuO}_{2} \mathrm{NiO}$ are operated at $\mathrm{pH}$ 8.5 and 5.5, respectively. 

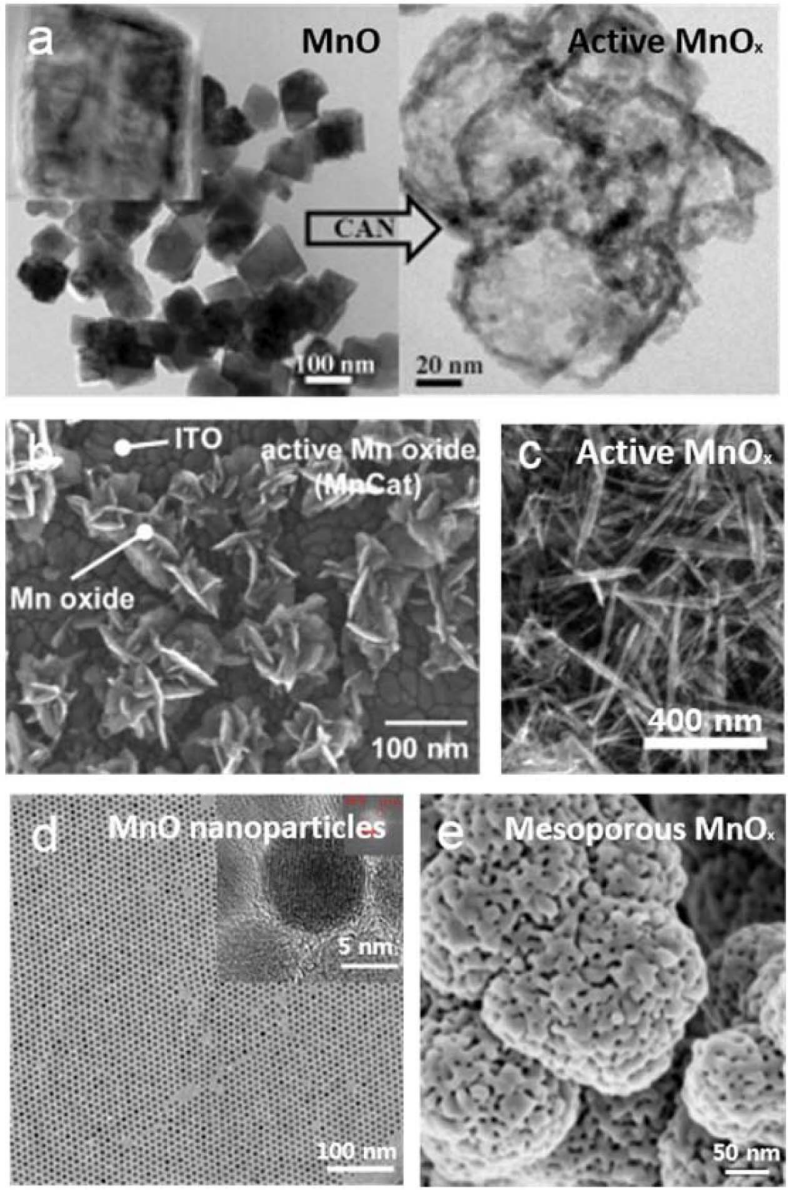

Fig. 3. Morphology of representative Mn-based electro-catalysts. (a) inactive crystalline $\mathrm{MnO}$ (left) and active amorphous $\mathrm{MnO}_{\mathrm{x}}$ (right) after partial oxidation by ceric ammonium nitrate (CAN), (b) electrodeposited $\mathrm{MnO}_{x}$ active catalysts, (c) activated $\mathrm{MnO}_{x}$ catalysts, (d) mono-dispersed $10 \mathrm{~nm}$-sized $\mathrm{MnO}$ nano-catalysts synthesized by hot-injection method and (e) mesoporous $\mathrm{MnO}_{\mathrm{x}}$ synthesized by soft-templated method.

mance as the Mn oxidation states increased. ${ }^{16)}$ Recently, they further developed partially oxidized monodisperse 10 $\mathrm{nm} \mathrm{MnO}$ nanoparticles by conventional hot-injection method (Fig. 3(d)). ${ }^{17)}$ Furthermore, they synthesized Mnbased oxide nanoparticles with various phases such as $\mathrm{Mn}_{5} \mathrm{O}_{8}$ and found that the water-splitting efficiency of nanosized manganese oxide nanoparticles was superior to that of bulk-sized manganese oxides. ${ }^{18)}$

\subsection{Cobalt based electrocatalysts}

Cobalt based electrocatalysts for water oxidation have been largely reported in company with manganese based ones. A notable cobalt based electrocatalyst is cobalt phosphate(Co-Pi), reported by the Nocera group; it was found that this material could be easily deposited on indium tin oxide (ITO) or other inert anodes by anodic polarization in neutral Co(II) containing phosphate solution. ${ }^{19)}$ The group determined that an amorphous cobalt oxide film was formed

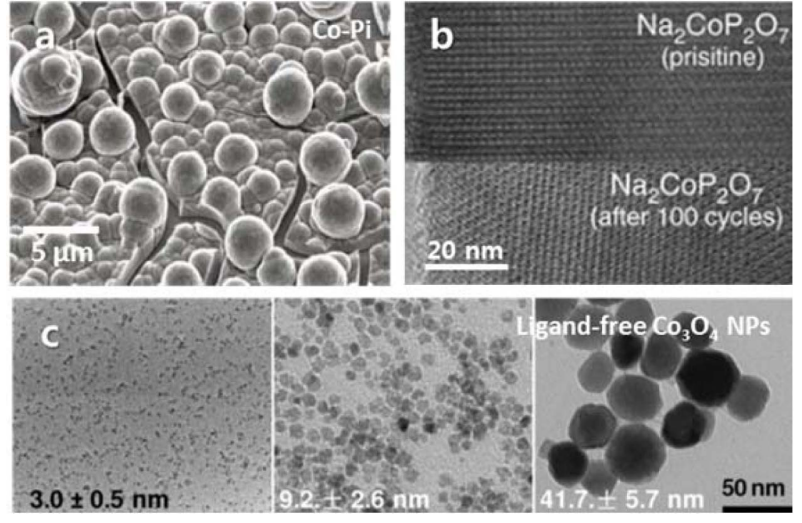

Fig. 4. Morphology of representative Co-based electro-catalysts. (a) Cobalt phosphate catalysts electrodeposited on indium tin oxide electrode, (b) surface region of $\mathrm{Na}_{2} \mathrm{CoP}_{2} \mathrm{O}_{7}$ before and after catalysis and (c) ligandfree $\mathrm{Co}_{3} \mathrm{O}_{4}$ nanoparticles with various sizes noted in each images.

during electrodeposition in a neutral phosphate solution (Fig. 4(a)); its oxygen evolving performance under such mild conditions was highly active, with almost 100\% Faradaic efficiency. Furthermore, Co-Pi was found to be able to sustainably catalyze the water oxidation reaction through the self-repair process, in which the in situ formation of Co-Pi occurred during catalysis in $\mathrm{Co}(\mathrm{II})$ containing phosphate solution at $\mathrm{pH} 7$.

Of relevance to the Co-Pi material, Nam's group reported $\mathrm{Na}_{2} \mathrm{CoP}_{2} \mathrm{O}_{7}$ with high catalytic activity and phase stability in $0.5 \mathrm{M}$ sodium phosphate buffer at $\mathrm{pH} 7$; this material was different from the conventional cobalt based electrocatalysts in terms of its local structure of cobalt and a water oxidizing mechanism including a dissimilar rate determining step (Fig. 4(b)). ${ }^{20)}$ In contrast with the five- and six-coordinated octahedral $\mathrm{Co}-\mathrm{Pi}$ with stabilized $\mathrm{Co}$ (III)/Co(IV) valence states, $\mathrm{Na}_{2} \mathrm{CoP}_{2} \mathrm{O}_{7}$ has a four- and five-coordinated tetrahedral structure with stabilized $\mathrm{Co}(\mathrm{II}) / \mathrm{Co}(\mathrm{III})$ valence states, which enables a minimization of the theoretical overpotential for water oxidation. ${ }^{21,22)}$ This work suggested that the catalytic activity for OER could be enhanced by tuning the atomic geometry of metal oxides.

Nanostructured cobalt oxides have also been suggested as water oxidizing electrocatalysts that can show improved electrochemical properties compared with those of conventional bulk cobalt oxides. ${ }^{23-25)} \mathrm{A}$ representative example is the ligand-free $\mathrm{Co}_{3} \mathrm{O}_{4}$ nanoparticles reported by Wang's group in $2013{ }^{23)}$ They synthesized and compared various spinel-type $\mathrm{Co}_{3} \mathrm{O}_{4}$ nanoparticles with different sizes (Fig. 4(c)) and concluded that the catalytic properties in neutral $0.1 \mathrm{M}$ potassium phosphate electrolyte could be enhanced by minimizing the particle size to increase the surface area available for water oxidation.

In addition, Meyer's group introduced cobalt-modified fluorine-doped tin oxide (FTO) to water oxidation catalysis in $0.1 \mathrm{M}$ phosphate with $0.5 \mathrm{M}$ added $\mathrm{NaClO}_{4}$ at $\mathrm{pH} 7.2 .{ }^{26)}$ 
They suggested that, with deprotonation, the surface-bound Co(II) species would be oxidized to Co(III) and successively participate in water oxidation catalysis; this process could be maximized by increasing the surface area of the FTO substrate.

\subsection{Nickel based electrocatalysts}

Rresearch on Ni-based catalyst for water oxidation was started by Bode in $1966 .{ }^{27)}$ Research on Ni-based catalysts has been primarily done in alkaline conditions, but there are some experiments that have implemented neutral conditions; we will discuss those experiments below.

Juodkazis's group thermally deposited $\mathrm{RuO}_{2}$ and $\mathrm{NiO}$ oxides on a titanium electrode and found that, in a neutral solution of $\mathrm{K}_{2} \mathrm{SO}_{4}(\mathrm{pH}=5.5)$, the oxygen evolution process was significantly hindered. ${ }^{28)}$ In their subsequent research, nickel surface anodic oxidation was implemented prior to the oxygen evolution reaction and the changes in the surface state of the nickel electrode in acid, neutral and alkaline solutions were investigated and found to show the beginnings of an oxygen evolution reaction at $\sim 2.0 \mathrm{~V}$ (vs. $\mathrm{RHE})$ in neutral medium $(\mathrm{pH}=5.5){ }^{29)}$

Nocera's group electrodeposited a nickel-borate catalyst from dilute $\mathrm{Ni}^{2+}$ solution in a borate electrolyte at $\mathrm{pH} 9.2 .^{30}$ In further research, they performed Tafel analysis in various $\mathrm{pH}$ conditions ranging from $\mathrm{pH}$ 8.5 14; their calculated Tafel slope was $32 \mathrm{mV} /$ decade in well-buffered electrolytes at $\mathrm{pH} 8.5 .^{31)}$

\subsection{Iron and Copper based electrocatalysts}

While $\mathrm{Mn}, \mathrm{Ni}$ and Co based heterogeneous electrocatalysts have been suggested for their great oxygen evolving activity and stability under neutral conditions, iron or copper based electrocatalysts have only rarely been studied. Rather, iron or copper has been reported as an active metal site in molecular catalysts for water oxidation, in the following examples: Masaoka's group designed a pentanuclear iron catalyst with great efficiency and redox flexibility. ${ }^{32)}$ They confirmed six different oxidation states of the pentanuclear iron complex and defined an active state for water oxidation, the $\mathrm{Fe}(\mathrm{III})_{5}$ state. In the case of copper based molecular catalysts, Meyer's group investigated a copper(II) polypeptide complex, the triglycylglycine macrocyclic ligand $\left(\mathrm{TGG}^{4}\right)$ complex of $\mathrm{Cu}(\mathrm{II})$, for efficient water oxidation. ${ }^{33)}$ They suggested a water oxidation mechanism of the coppercored polypeptide complex, in which activated $\mathrm{Co}(\mathrm{IV})$ species would oxidize water and release dioxygen with high stability and turnover frequency.

\section{Water oxidation mechanism}

The water oxidation reaction is a 4-electron, 4-proton process; O-O bond formation is known to be the key chemical step that determines the rate of the whole water oxidation reaction. To develop a catalyst for the water oxidation reaction based on earth-abundant $3 \mathrm{~d}$ transition metal oxides, many material factors were controlled such as the composition, phase, morphology and surface structure. However, the precise roles of each component and factor influencing the performance are still not clear. As a result, understanding the reaction mechanism is very important and necessary to rationally design catalysts having superior activity, stability and selectivity.

Investigation of the rate-determining step (RDS) and of the reaction intermediates is thus important to understand the reaction mechanism. Two mechanisms are proposed for $\mathrm{O}-\mathrm{O}$ bond formation, which is the RDS in the water oxidation reaction. (Fig. 5) The acid (electrophilic)-base (nucleophilic) $(\mathrm{AB})$ mechanism proposed by the Shannon and Frei groups explains that octahedral metal-oxo sites act as mononuclear active sites. Because these metal-oxo sites are considered to be electrophilic, a nucleophilic attack of water molecules naturally occurs to generate peroxo intermediates. On the other hand, the radical coupling (RC) mechanism was proposed by the Najafpour and Voorhis groups. They predicted that the di-nuclear O-O bond formation by adjacent metal-oxo species was the energetically favorable reaction route. Here, we introduce and summarize recent studies on the reaction mechanism for water oxidation catalyzed by $3 \mathrm{~d}$ transition metal oxides.

\subsection{Acid-Base mechanism}

For earth-abundant metal-oxide catalysts, Shannon's group proposed a mechanism of cobalt-catalyzed water oxidation in aqueous buffering electrolytes in a $\mathrm{pH}$ range of 0 $14{ }^{22)}$ Through combined electrokinetic, cyclic voltammetry and electron paramagnetic resonance (EPR) spectroscopic studies, they concluded that Co(IV)-oxo species are crucial intermediates for $\mathrm{O}-\mathrm{O}$ bond formation. Cobalt metal has mixed valency, with $+3 /+4$ states present in the resting state; Co(IV)-oxo species were generated before RDS. Water molecules react with this $\mathrm{Co}(\mathrm{IV})$-oxo intermediate to generate the $\mathrm{O}-\mathrm{O}$ bond. The researchers excluded the possibility of a reaction with lattice oxygen atoms because no oxygen gas evolved in the absence of water. ${ }^{34,35)}$

To compare the relative stability and activity of various layered cobalt oxide phases, the Bell group performed computational calculations using density functional theory. ${ }^{21)}$ They found that $\mathrm{B}-\mathrm{CoOOH}$ is the active phase, in which the OER occurs in an alkaline environment and the catalytic activity can be attributed to the high valence of $\mathrm{Co}$ metal $(3+/ 4+)$ during the OER. The $\mathrm{AB}$ mechanism was used to explain $\mathrm{O}-\mathrm{O}$ bond formation, because the thermodynamic energy barrier for surface oxygen coupling is almost always larger than associative reaction. ${ }^{36)}$

Mechanisms of the other 3d transition metal based catalysts are also reported. For example, Nocera's group studied the water oxidation mechanism of electrodeposited manganese oxide $\left(\mathrm{MnO}_{\mathrm{x}}\right){ }^{37)}$ Through electrokinetic study over a wide $\mathrm{pH}$ range, they suggested two competing mechanisms. A one-electron one-proton pair is removed from the surface of manganese oxide via proton coupled electron transfer 


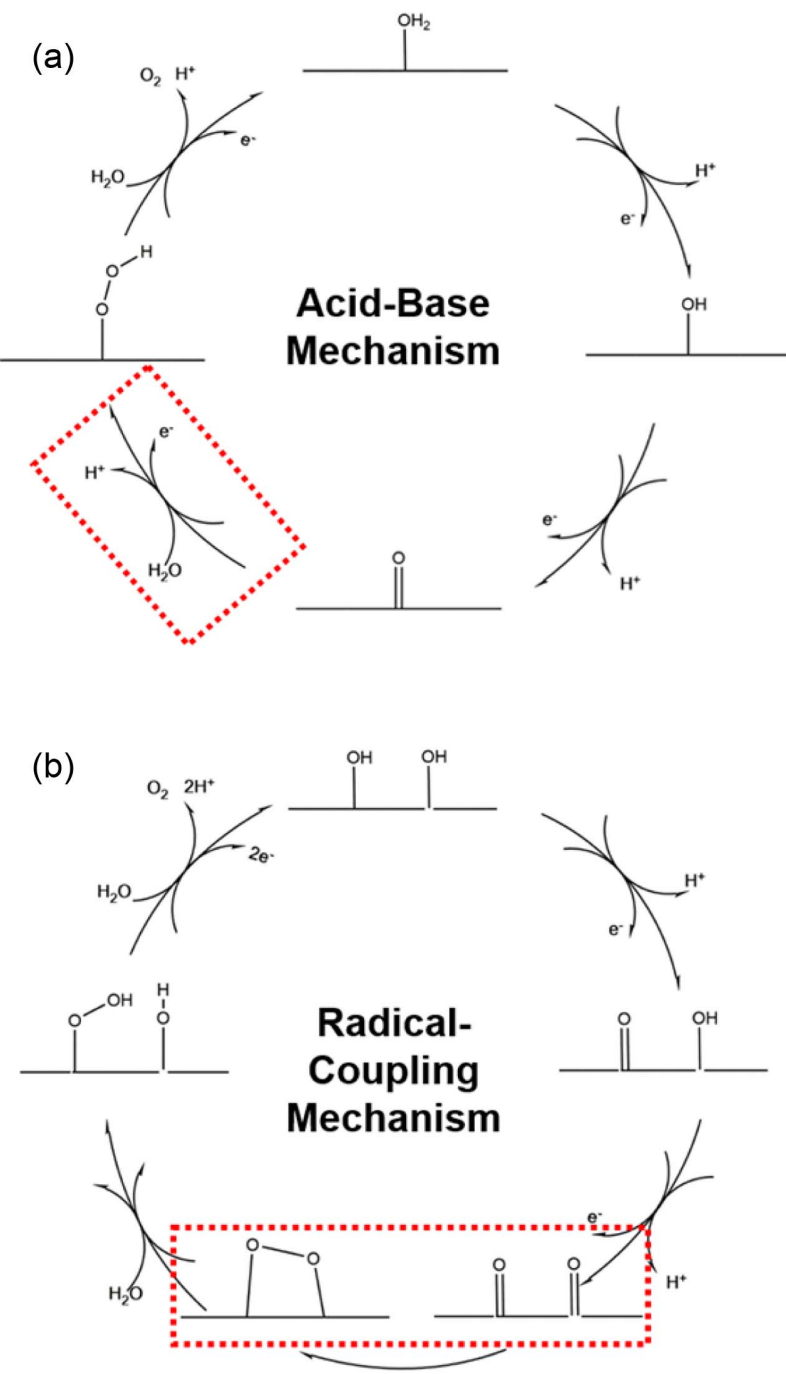

Fig. 5. Schematic representation of water oxidation mechanism (a) Acid-Base (AB) mechanism for O-O bond formation (b) Radical-Coupling (RC) mechanism for O-O bond formation.

(PCET), which is dominant under alkaline conditions; $\mathrm{Mn}^{3+}$ disproportionation mainly occurs under acidic conditions. Finally, $\mathrm{Mn}(\mathrm{IV})=\mathrm{O}$ sites were generated and $\mathrm{O}_{2}$ molecules evolved from those terminal oxo sites. Very recently, Nam's group performed in-situ spectroscopic and electrokinetic analyses to reveal the mechanism of partially-oxidized manganese oxide nanoparticles, which were shown to exhibit a superior OER property at neutral pH (Fig. 6(a)). They found that the partially oxidized manganese oxide nanoparticle system shows different mechanistic behavior; the generation of $\mathrm{Mn}^{3+}$ is no longer the RDS for the water oxidation reaction. The $\mathrm{Mn}(\mathrm{IV})=\mathrm{O}$ species were generated as reaction intermediates and $\mathrm{O}_{2}$ was generated from these oxo sites through the $\mathrm{AB}$ mechanism.

Indeed, the $\mathrm{AB}$ mechanism from high-valent metal-oxo species has been commonly suggested, especially as the water oxidation mechanism of heterogeneous $3 \mathrm{~d}$ transition (a)

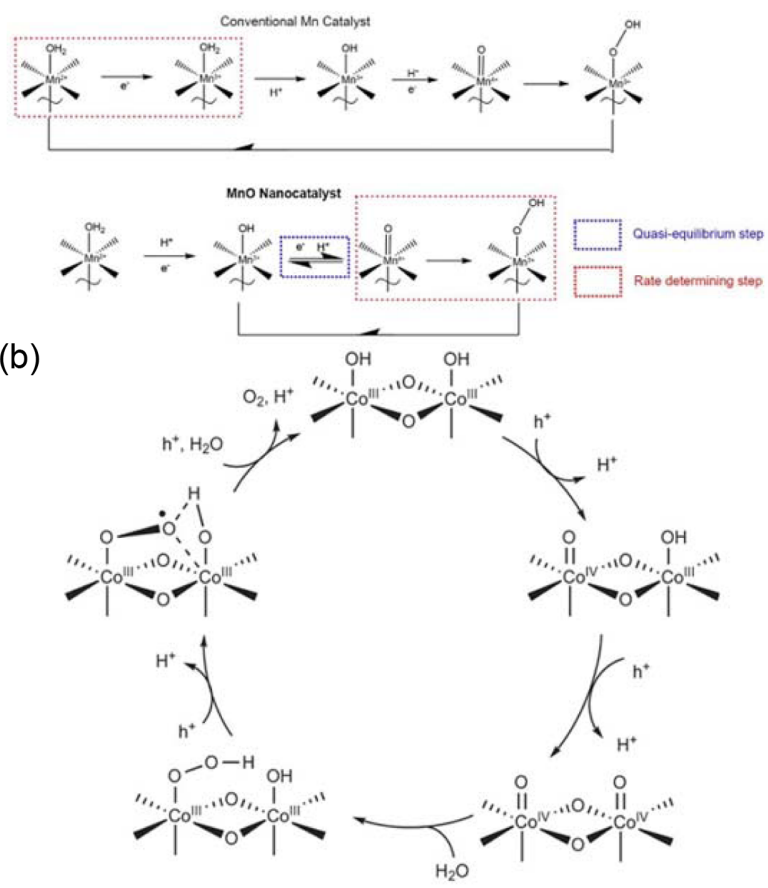

Fig. 6. Schematic representation of Acid-Base mechanism for water oxidation reaction. Proposed mechanisms of (a) partially oxidized manganese oxide nanoparticles at neutral $\mathrm{pH}$ by Nam's group and (b) cobalt oxide nanoparticles $\left(\mathrm{Co}_{3} \mathrm{O}_{4}\right)$ by Frei's group.

metal oxide catalysts. Recently, important reaction intermediates were characterized by Frei's group. ${ }^{38)}$ They performed time-resolved Fourier-transform infrared (FT-IR) spectroscopy to identify stepwise cobalt intermediate structures in the catalysis. Two surface intermediates of $\mathrm{Co}_{3} \mathrm{O}_{4}$ were observed by rapid-scan FT-IR spectroscopy with ${ }^{18} \mathrm{O}$ isotope labeling experiment. A surface superoxide intermediate and $\mathrm{Co}(\mathrm{IV})=\mathrm{O}$ were detected for the fast catalytic site and slow catalytic site, respectively (Fig. 6(b)). Observation of a surface superoxide intermediate (three-electron oxidation intermediate) would be another important piece of evidence of the proposed mechanism of cobalt oxide. One structural difference between the two intermediates is the nature of the coupling among adjacent $\mathrm{Co}(\mathrm{III})-\mathrm{OH}$ groups via oxygen bridges, which results in a huge catalytic activity difference.

\subsection{Radical-Coupling mechanism}

The $\mathrm{RC}$ mechanism is also a feasible pathway to generate $\mathrm{O}-\mathrm{O}$ bonds during water oxidation. In the $\mathrm{RC}$ mechanism, $\mathrm{O}-\mathrm{O}$ bonding is constructed by coupling of two adjacent $\mathrm{M}=\mathrm{O}$ species because $\mathrm{M}=\mathrm{O}$ species are isoelectric structures of radical species (M-O). Generally, based on spectroscopic evidence, the $\mathrm{RC}$ pathway has been proposed for $\mathrm{O}-\mathrm{O}$ bond formation in molecular complex catalysts. However, it was recently reported that the generation of O-O bonding in inorganic catalysts can also be attributed to coupling of two metal-oxo species. 
The Sun group reported Ru- based molecular catalysts that exhibited an unprecedentedly high turnover frequency (TOF) of $>300 \mathrm{~s}^{-1}{ }^{6}$ ) For the molecular catalyst $\mathrm{Ru}(\mathrm{II})-\mathrm{OH}_{2}$, the resting state of the active sites was oxidized to $\mathrm{Ru}(\mathrm{III})$ $\mathrm{OH}_{2}$ and two consecutive oxidation processes generated a reaction intermediate, $\mathrm{Ru}(\mathrm{V})=\mathrm{O}$, via proton coupled electron transfer $(\mathrm{PCET})$. Interestingly, the $\mathrm{Ru}(\mathrm{V})=\mathrm{O}$ species were dimerized to $\mathrm{Ru}(\mathrm{IV})$ peroxo dimer, $\mathrm{Ru}(\mathrm{IV})-\mathrm{OO}-\mathrm{Ru}(\mathrm{IV})$, which was detected by UV-vis spectroscopy. Based on the spectroscopic data, it was concluded that the O-O bond formation had progressed by direct coupling of two $\mathrm{Ru}(\mathrm{V})=\mathrm{O}$ species. Furthermore, the group suggested that organic ligands facilitated the radical dimerization of the $\mathrm{Ru}(\mathrm{V})=\mathrm{O}$ active species.

The RC pathway was also proposed for the formation of O$\mathrm{O}$ bonds in $3 \mathrm{~d}$ transition metal oxide catalysts. Najafpour's group investigated the $\mathrm{O}-\mathrm{O}$ bond formation mechanism using nano-layered $\mathrm{MnO}_{\mathrm{x}}$ catalysts. ${ }^{39)}$ They estimated the exchange rate of $\mathrm{H}_{2}{ }^{18} \mathrm{O}$ for $\mathrm{\mu}-\mathrm{O}$ species (Mn-O-Mn) in $\mathrm{MnO}_{\mathrm{x}}$ during catalysis. Spectra from diffuse reflectance infrared Fourier transform spectroscopy (DRIFTS) analysis of the $\mu$ $\mathrm{O}$ species did not change during catalysis in $\mathrm{H}_{2}{ }^{18} \mathrm{O}$. These results indicate that the oxygen atoms of the $\mu-\mathrm{O}$ species are not involved in the O-O bond formation. As can be seen in Fig. 7(a), the group suggested that not only the AB mechanism (pathway i) but also the RC mechanism (pathway ii) was feasible in the nano-layered $\mathrm{MnO}_{\mathrm{x}}$.

The Voorhis group theoretically investigated the water oxidizing mechanism of Co-Pi. As shown in Fig. 7(b), two adjacent $\mathrm{Co}(\mathrm{III})-\mathrm{OH}$ species were oxidized to $\mathrm{Co}(\mathrm{IV})=\mathrm{O}$ via a proton-coupled oxidation process. ${ }^{40)}$ Through electrokinetic study, Nocera's group corroborated the proton-coupled oxidation step. The free energy barrier to O-O single bond formation was computed using DFT study. Based on the computation results, direct coupling of $\mathrm{Co}(\mathrm{IV})=\mathrm{O}$ in the cubane structure was suggested as a more favorable reaction pathway. Additionally, the free energy profile as a function of the O-O bond distance additionally supported the idea that direct coupling occurs spontaneously in cobalt catalysts.

\section{Summary}

In this review, we have covered recent advances in the development of $3 \mathrm{~d}$ transition metal oxides for water oxidation electrocatalysts. $\mathrm{Mn}, \mathrm{Co}$ and $\mathrm{Ni}$ oxides have been extensively reported as efficient electrocatalysts under neutral condition, whereas $\mathrm{Fe}$ and $\mathrm{Cu}$ oxides have been only rarely synthesized. The manganese-based catalysts with mixed valency of $\mathrm{Mn}(\mathrm{III})$ and $\mathrm{Mn}(\mathrm{IV})$ exhibited moderate activity under neutral condition. For Co and Ni oxide-based electrocatalysts, the Nocera group synthesized $\mathrm{Co}-\mathrm{Pi}$ and $\mathrm{Ni}-\mathrm{Bi}$ using the electrodeposition method; the resulting materials show benign efficiency at neutral $\mathrm{pH}$. Moreover, revealing the detailed water oxidation mechanism is a demanding issue. In this review, we have demonstrated two hypotheses (a)
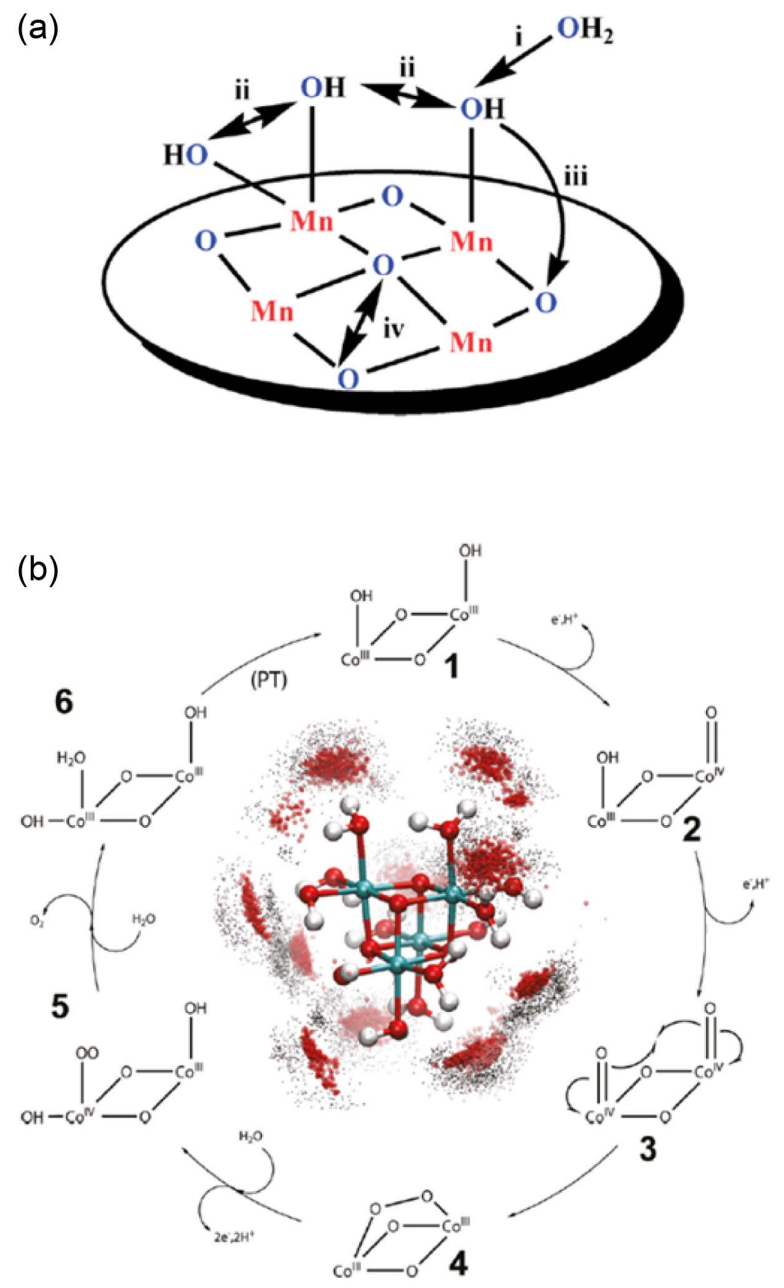

Fig. 7. Schematic representation of radical coupling mechanism for water oxidation reaction. Proposed mechanisms of (a) nanolayered manganese oxide by the Najafpour group and (b) Co-Pi, by the Voorhis group.

(the $\mathrm{AB}$ mechanism and the $\mathrm{RC}$ mechanism) for $\mathrm{O}-\mathrm{O}$ bond formation, which is the rate determining step for water oxidation. Generally, O-O bond formation in $3 \mathrm{~d}$ transition metal oxides has been demonstrated to occur according to the $\mathrm{AB}$ mechanism, which generates a single $\mathrm{O}-\mathrm{O}$ bond via nucleophilic attack. The RC mechanism is generally used to explain the formation of $\mathrm{O}-\mathrm{O}$ bonds for molecular catalysts. Recently, it was revealed that the RC mechanism had also been suggested for the $3 \mathrm{~d}$ transition metal oxides. To shed more light on the process of $\mathrm{O}-\mathrm{O}$ bond formation, more advanced in-situ analysis, such as time-resolved spectroscopic measurement, is required.

\section{Acknowledgments}

This work was supported by the KIST Institutional Program (Project No. 2E00000). 


\section{REFERENCES}

1. M. Dresselhaus and I. Thomas, "Alternative Energy Technologies," Nature, 414 [6861] 332-37 (2001).

2. J. O. M. Bockris and T. N. Veziroglu, "Estimates of the Price of Hydrogen as a Medium for Wind and Solar Sources," Int. J. Hydrogen Energy, 32 [12] 1605-10 (2007).

3. I. C. Man, H. Y. Su, F. Calle-Vallejo, H. A. Hansen, J. I. Martínez, N. G. Inoglu, J. Kitchin, T. F. Jaramillo, J. K. Nørskov, and J. Rossmeisl, "Universality in Oxygen Evolution Electrocatalysis on Oxide Surfaces," Chem CatChem, 3 [7] 1159-65 (2011).

4. H. Dau, C. Limberg, T. Reier, M. Risch, S. Roggan, and P. Strasser, "The Mechanism of Water Oxidation: from Electrolysis via Homogeneous to Biological Catalysis," ChemCatChem, 2 [7] 724-61 (2010).

5. C. C. McCrory, S. Jung, J. C. Peters, and T. F. Jaramillo "Benchmarking Heterogeneous Electrocatalysts for the Oxygen Evolution Reaction," J. Am. Chem. Soc., 135 [45] 16977-87 (2013).

6. L. Duan, F. Bozoglian, S. Mandal, B. Stewart, T. Privalov, A. Llobet, and L. Sun, "A Molecular Ruthenium Catalyst with Water-Oxidation Activity Comparable to that of Photosystem II," Nat. Chem., 4 [5] 418-23 (2012).

7. M. Yagi, E. Tomita, S. Sakita, T. Kuwabara, and K. Nagai, "Self-Assembly of Active $\mathrm{IrO}_{2}$ Colloid Catalyst on an ITO Electrode for Efficient Electrochemical Water Oxidation," J. Phys. Chem. B, 109 [46] 21489-91 (2005).

8. R. D. Smith, B. Sporinova, R. D. Fagan, S. Trudel, and C. P. Berlinguette, "Facile Photochemical Preparation of Amorphous Iridium Oxide Films for Water Oxidation Catalysis," Chem. Mater., 26 [4] 1654-59 (2014).

9. A. Indra, P. W. Menezes, I. Zaharieva, E. Baktash, J. Pfrommer, M. Schwarze, H. Dau, and M. Driess, "Active Mixed-Valent $\mathrm{MnOx}$ Water Oxidation Catalysts through Partial Oxidation (Corrosion) of Nanostructured MnO Particles," Angew. Chem., Int. Ed., 52 [50] 13206-10 (2013).

10. I. Zaharieva, P. Chernev, M. Risch, K. Klingan, M. Kohlhoff, A. Fischer, and H. Dau, "Electrosynthesis, Functional, and Structural Characterization of a Water-Oxidizing Manganese Oxide," Energy Environ. Sci., 5 [5] 7081-89 (2012).

11. M. Huynh, C. Shi, S. J. Billinge, and D. G. Nocera, "Nature of Activated Manganese Oxide for Oxygen Evolution," $J$. Am. Chem. Soc., 137 [47] 14887-904 (2015).

12. C.-H. Kuo, I. M. Mosa, A. S. Poyraz, S. Biswas, A. M. ElSawy, W. Song, Z. Luo, S.-Y. Chen, J. F. Rusling, and J. He, "Robust Mesoporous Manganese Oxide Catalysts for Water Oxidation," ACS Catal., 5 [3] 1693-99 (2015).

13. T. Takashima, K. Hashimoto, and R. Nakamura, "Mechanisms of pH-Dependent Activity for Water Oxidation to Molecular Oxygen by $\mathrm{MnO}_{2}$ Electrocatalysts," J. Am. Chem. Soc., 134 [3] 1519-27 (2012).

14. T. Takashima, K. Hashimoto, and R. Nakamura, "Inhibition of Charge Disproportionation of $\mathrm{MnO}_{2}$ Electrocatalysts for Efficient Water Oxidation under Neutral Conditions," $J$. Am. Chem. Soc., 134 [44] 18153-56 (2012).

15. K. Jin, J. Park, J. Lee, K. D. Yang, G. K. Pradhan, U. Sim, D. Jeong, H. L. Jang, S. Park, D. Kim, and K. T. Nam,
"Hydrated Manganese (II) Phosphate $\left(\mathrm{Mn}_{3}\left(\mathrm{PO}_{4}\right)_{2} \cdot 3 \mathrm{H}_{2} \mathrm{O}\right)$ as a Water Oxidation Catalyst," J. Am. Chem. Soc., 136 [20] 7435-43 (2014).

16. J. Park, H. Kim, K. Jin, B. J. Lee, Y.-S. Park, H. Kim, I. Park, K. D. Yang, H.-Y. Jeong, and J. Kim, "A New Water Oxidation Catalyst: Lithium Manganese Pyrophosphate with Tunable Mn Valency," J. Am. Chem. Soc., 136 [11] 4201-11 (2014).

17. K. Jin, A. Chu, J. Park, D. Jeong, S. E. Jerng, U. Sim, H.-Y. Jeong, C. W. Lee, Y.-S. Park, K. D. Yang, and K. T. Nam "Partially Oxidized Sub-10 nm MnO Nanocrystals with High Activity for Water Oxidation Catalysis,” Sci. Rep., 5 [10279] (2015).

18. D. Jeong, K. Jin, S. E. Jerng, H. Seo, D. Kim, S. H. Nahm, S. H. Kim, and K. T. Nam, " $\mathrm{Mn}_{5} \mathrm{O}_{8}$ Nanoparticles as Efficient Water Oxidation Catalysts at Neutral pH," ACS Catal., 5 [8] 4624-28 (2015).

19. M. W. Kanan and D. G. Nocera, "In Situ Formation of an Oxygen-Evolving Catalyst in Neutral Water Containing Phosphate and $\mathrm{Co}^{2+}$," Science, 321[5892] 1072-75 (2008).

20. H. Kim, J. Park, I. Park, K. Jin, S. E. Jerng, S. H. Kim, K. T. Nam, and K. Kang, "Coordination Tuning of Cobalt Phosphates towards Efficient Water Oxidation Catalyst," Nat. Commun., 68253 (2015).

21. M. Bajdich, M. García-Mota, A. Vojvodic, J. K. Nørskov, and A. T. Bell, "Theoretical Investigation of the Activity of Cobalt Oxides for the Electrochemical Oxidation of Water," J. Am. Chem. Soc., 135 [36] 13521-30 (2013).

22. J. B. Gerken, J. G. McAlpin, J. Y. Chen, M. L. Rigsby, W. H. Casey, R. D. Britt, and S. S. Stahl, "Electrochemical Water Oxidation with Cobalt-Based Electrocatalysts from pH 0-14: the Thermodynamic Basis for Catalyst Structure, Stability, and Activity," J. Am. Chem. Soc., 133 [36] 1443142 (2011).

23. M. Grzelczak, J. Zhang, J. Pfrommer, J. Hartmann, M. Driess, M. Antonietti, and X. Wang, "Electro-and Photochemical Water Oxidation on Ligand-Free $\mathrm{Co}_{3} \mathrm{O}_{4}$ Nanoparticles with Tunable Sizes," ACS Catal., 3 [3] 383-88 (2013).

24. J. D. Blakemore, H. B. Gray, J. R. Winkler, and A. M. Muller, " $\mathrm{Co}_{3} \mathrm{O}_{4}$ Nanoparticle Water-Oxidation Catalysts Made by Pulsed-Laser Ablation in Liquids," ACS Catal., 3 [11] 2497-500 (2013).

25. F. Jiao and H. Frei, "Nanostructured Cobalt Oxide Clusters in Mesoporous Silica as Efficient Oxygen-Evolving Catalysts," Angew. Chem., 121 [10] 1873-76 (2009).

26. C. A. Kent, J. J. Concepcion, C. J. Dares, D. A. Torelli, A. J. Rieth, A. S. Miller, P. G. Hoertz, and T. J. Meyer, "Water Oxidation and Oxygen Monitoring by Cobalt-Modified Fluorine-Doped Tin Oxide Electrodes," J. Am. Chem. Soc., 135 [23] 8432-35 (2013).

27. H. Bode, K. Dehmelt, and J. Witte, "Zur Kenntnis der Nickelhydroxidelektrode-I. Über das Nickel (II)-Hydroxidhydrat," Electrochim. Acta, 11 [8] 1079IN1-87 (1966).

28. K. Juodkazis, J. Juodkazytè, R. Vilkauskaite, B. Sebeka, and V. Jasulaitiene, "Oxygen Evolution on Composite Ruthenium and Nickel Oxides Electrode," Chemija, 19 [1] 1-6 (2008).

29. K. Juodkazis, J. Juodkazytè, R. Vilkauskaitè, and V. Jasulaitiene, "Nickel Surface Anodic Oxidation and Electroca- 
talysis of Oxygen Evolution,” J. Solid State Electrochem., 12 [11] 1469-79 (2008).

30. M. Dincă, Y. Surendranath, and D. G. Nocera, "NickelBorate Oxygen-Evolving Catalyst that Functions under Benign Conditions," Proc. Natl. Acad. Sci., 107 [23] 1033741 (2010).

31. D. K. Bediako, Y. Surendranath, and D. G. Nocera, "Mechanistic Studies of the Oxygen Evolution Reaction Mediated by a Nickel-Borate Thin Film Electrocatalyst," J. Am. Chem. Soc., 135 [9] 3662-74 (2013).

32. M. Okamura, M. Kondo, R. Kuga, Y. Kurashige, T. Yanai, S. Hayami, V. K. Praneeth, M. Yoshida, K. Yoneda, and S. Kawata, "A pentanuclear Iron Catalyst Designed for Water Oxidation," Nature, 530 465-68 (2016).

33. M.-T. Zhang, Z. Chen, P. Kang, and T. J. Meyer, "Electrocatalytic Water Oxidation with a Copper (II) Polypeptide Complex," J. Am. Chem. Soc., 135 [6] 2048-51 (2013).

34. K. Takada, K. Fukuda, M. Osada, I. Nakai, F. Izumi, R. A. Dilanian, K. Kato, M. Takata, H. Sakurai, E. T.-Muromachi, and T. Sasaki, "Chemical Composition and Crystal Structure of Superconducting Sodium Cobalt Oxide Bilayer-Hydrate," J. Mater. Chem., 14 [9] 1448-53 (2004).
35. T. Motohashi, Y. Katsumata, T. Ono, R. Kanno, M. Karppinen, and H. Yamauchi, "Synthesis and Properties of $\mathrm{CoO}_{2}$, the $\mathrm{x}=0$ End Member of the $\mathrm{Li}_{\mathrm{x}} \mathrm{CoO}_{2}$ and $\mathrm{Na}_{\mathrm{x}} \mathrm{CoO}_{2}$ Systems," Chem. Mater., 19 [21] 5063-66 (2007).

36. J. K. Nørskov, T. Bligaard, A. Logadottir, S. Bahn, L. B. Hansen, M. Bollinger, H. Bengaard, B. Hammer, Z. Sljivancanin, M. Mavrikakis, Y. Xu, S. Dahl, and C. J. H. Jacobsen, "Universality in Heterogeneous Catalysis," J. Catal., 209 [2] 275-78 (2002).

37. M. Huynh, D. K. Bediako, and D. G. Nocera, "A Functionally Stable Manganese Oxide Oxygen Evolution Catalyst in Acid,” J. Am. Chem. Soc., 136 [16] 6002-10 (2014).

38. M. Zhang, M. de Respinis, and H. Frei, "Time-Resolved Observations of Water Oxidation Intermediates on a Cobalt Oxide Nanoparticle Catalyst," Nat. Chem., 6 362-67 (2014).

39. M. M. Najafpour and M. A. Isaloo, "Mechanism of Water Oxidation by Nanolayered Manganese Oxide: A Step Forward," RSC Advances, 4 [13] 6375-78 (2014).

40. L.-P. Wang and T. V. Voorhis, "Direct-Coupling $\mathrm{O}_{2}$ Bond Forming a Pathway in Cobalt Oxide Water Oxidation Catalysts,” J. Phys. Chem. Lett., 2 [17] 2200-4 (2011). 